Revista de Economia Política, vol. 33, n 2 (131), pp. 281-297, abril-junho/2013

\title{
Lei e ordem econômica no pensamento de John R. Commons
}

\section{SEBASTIÃO GUEDES*}

Law and economic order in John R.Commons thought. The paper has analyzed John R. Commons' contribution to the comprehension of Law and Economics relationship. In contrast to the orthodox economics, Commons has shown that the capitalist economic order emerges and functions regulated by laws and institutions. These approaches made possible to him to understand the nature of the modern capitalist wealth and the problems that time introduces in economic transactions.

Keywords: institutional economics; law and economics; regulated order.

JEL Classification: B15; B31.

\section{INTRODUÇÃO}

John R. Commons (1862-1945) foi uma das figuras líderes na trajetória de economia heterodoxa conhecida como Economia Institucional, que, entre o final do século XIX e o início da Segunda Guerra Mundial, foi influente no cenário intelectual norte-americano (Renault, 1997; Klein, 1990; Baslé,1993). A tríade dos mais famosos institucionalistas incluía, além de Commons, também Veblen e Mitchell. Escola heterogênea, a Economia Institucional reivindicava uma perspectiva dinâmica e evolucionista para o estudo do capitalismo, e atribuía às instituições o protagonismo nos processos de conservação e mudança econômicas. Ela também defendia a interdisciplinaridade como recurso de investigação para lidar com a complexidade da sociedade capitalista, reconhecendo as contribuições da Ciência Política, da Sociologia, da Psicologia e de outras ciências. Por fim, propunha uma abordagem holística e histórica do material empírico referente às instituições so-

\footnotetext{
"Professor Doutor do Departamento de Economia da Universidade Estadual Paulista "Júlio de Mesquita Filho” (Unesp/Araraquara). E-mail: sebaneto@fclar.unesp.br. Submetido: 14/dezembro/2011; Aprovado: 25/maio/2012.
} 
cioeconômicas (Myrdal, 1978). No entanto, talvez a característica fundamental dessa escola consistisse na recusa radical do ponto de vista do individualismo metodológico (Hodgson, 2000).

Entre os institucionalistas, Commons se destacou por oferecer uma interpretação do capitalismo a partir do que chamou de valor "razoável", e de vinculá-la ao seu projeto de reformas que visavam "conter" os efeitos negativos do capitalismo, impondo-lhe ampla regulação (Hartes Jr, 1962). Nele teoria e prática estavam unidas, sendo expressão disso sua contribuição pessoal na "construção" de novas instituições no governo reformista de Phillip LaFollette, em Winsconsin, na segunda década do século XX. Igualmente relevante é sua teoria da ação coletiva, uma criativa reflexão sobre a ação humana para além do individualismo metodológico. Essa, aliás, tida por Mitchell (1950) como sua mais duradoura contribuição.

Atualmente observa-se um grande interesse pelo estudo das instituições em boa medida pelas mãos, até ironicamente, da versão ortodoxa da Economia Institucional, conhecida como Nova Economia Institucional (Dugger, 1990). Nesse contexto, a obra e o pensamento de Commons seguem no mesmo sentido, ampliando-se o número de reflexões e comentários sobre vários aspectos da sua teoria e prática política (Bazzoli, 1999:15). Apesar disso, esse importante autor permanece quase desconhecido dos economistas brasileiros, sendo evidência disso a inexistência de uma tradução brasileira de qualquer dos seus trabalhos. Esse artigo tem, assim, um papel também de divulgação. Mas seu objetivo principal não é esse. Ele pretende chamar a atenção para o modo particular por meio do qual Commons percebe as relações entre a economia e a lei e as articula para obter dois resultados: 1) oferecer uma explicação teórica alternativa para a emergência da ordem econômica e, como conseqüência desta, 2) explicar como se criam e legitimam as novas formas predominantes da riqueza capitalista, identificadas como incorpóreas e intangíveis.

Esse artigo divide-se em três seções, além dessa introdução. Na primeira apresentam-se os termos e argumentos gerais utilizados por Commons para conferir à transação a centralidade na análise econômica e dessa maneira problematizar as explicações em economia fundadas numa concepção de ordem espontânea; na segunda seção, realiza-se uma incursão pelo modo como Commons ressalta as afinidades entre o Direito e a Economia, enfatizando a necessidade de estabelecer "pontes" que façam convergir as duas disciplinas se se deseja compreender a emergência e permanência da ordem regulada. Na terceira seção procura-se, a guisa de síntese, discutir o papel da lei no que diz respeito à ancoragem legal das novas formas de riqueza características do capitalismo moderno. 


\section{TRANSAÇÕES, AÇÃO COLETIVA E ORDEM REGULADA}

Commons não foi o primeiro a analisar as relações entre lei e economia, mas certamente foi o que o fez com maior profundidade. ${ }^{1}$ Para ele o estudo das leis e a busca pelas bases jurídico-legais do capitalismo foi uma estratégia para rediscutir a natureza da ordem econômica moderna baseada nos mercados a partir de dois aspectos cruciais. O primeiro repousa em sua veemente discordância do ponto de vista formulado desde Smith, segundo o qual é possível o estabelecimento de uma ordem econômica estável e harmoniosa a partir das motivações e interações espontâneas dos indivíduos; o segundo, do parecer da mesma matriz teórica para quem os mecanismos de mercado, tendo como diretrizes os valores/preços, regulam exclusivamente o sistema econômico.

Para Commons, a primeira afirmação derivou da intenção de construir, à semelhança da física clássica, uma ciência mecânica submetida a leis somente discerníveis quando abstraídas dos seus condicionantes sociais. Isto conduziu os economistas clássicos (e depois os neoclássicos) a desconsiderarem as instituições, e a tratarem de uma perspectiva estática as interações humanas e seus resultados. Ao mesmo tempo, esse projeto intelectual dotou o indivíduo de certos atributos que foram eles mesmos resultados históricos. A esse respeito é esclarecedora sua observação de que

"Essas teorias de liberdade e racionalidade realizaram resultados extraordinários ao derrubarem as monarquias absolutistas, abolirem a escravidão e estabelecerem a educação universal. Mas isso aconteceu não porque elas fossem historicamente verdadeiras. Foi porque elas estabeleceram ideais de futuro. Historicamente é mais preciso dizer que o grosso da humanidade viveu em um estado de servidão, e que a liberdade veio gradualmente substituir esse estado. E historicamente é mais adequado dizer, como Malthus, que o homem é originalmente um ser de paixão e estupidez para quem a liberdade e a razão são uma questão de lenta evolução do caráter moral e da disciplina imposta pelo governo." (Commons, 2003:390) [Observação: todas as citações diretas encontradas nesse texto foram traduzidas pelo autor do artigo]

A segunda afirmação, por sua vez, tinha como ponto de partida a ênfase na troca e a crença de que ela realiza as funções de equilíbrio e estabilidade naturalmente, por meio das suas virtudes alocativas. Sua discordância nesse ponto em relação ao conhecimento estabelecido tinha a ver com a centralidade que Commons atribuía em sua análise à transação, contrapondo-a à troca (Mitchel, 1950: 318). A transação refere-se a um tipo de relação social entre pelo menos dois atores que

\footnotetext{
${ }^{1} \mathrm{O}$ próprio Commons reconheceu isto ao atribuir a McLeod o pioneirismo nessa matéria (COMMONS, 2003:394)
} 
buscam estabelecer, a partir de diferentes interesses e disputas, um comportamento mútuo adequado e relativamente estável. Ela sintetiza os elementos de conflito, dependência e ordem requeridos para as relações humanas pacíficas (Bazzo1i,1999:79). A esse respeito Commons (1995: 7-8) observou que:

"Embora os economistas comecem com a mercadoria ou um sentimento individual para com ela, a Corte Judicial começa com a transação. Sua unidade última de investigação não é um indivíduo, mas dois ou mais indivíduos - reclamante e réu - em dois extremos de uma ou mais transações. Mercadorias e sentimentos estão, certamente, subentendidos em todas as transações, contudo elas são apenas os preliminares, o acompanhamento ou o efeito das transações. A transação é composta de duas ou mais vontades dando, tomando, persuadindo, coagindo, defraudando, comandando, obedecendo, competindo, governando, em um mundo de escassez, mecanismos e regras de conduta. A Corte lida com a vontade em ação. Como a moderna física ou química, sua unidade última não é o átomo, mas um elétron, sempre em movimento — não um indivíduo, mas dois ou mais indivíduos em ação. Ela nunca os captura senão em movimento. Seu movimento é uma transação.”

O conceito de transação flagra assim os processos dinâmicos, complexos e nada harmoniosos de coordenação de interesses distintos na construção de regras estáveis de relacionamento. Adicionalmente, a transação não se reduzia à troca, um momento relacional específico no qual acontecia a transferência física de bens/ serviços (Pessali; Fernandez,1999). Isto porque a troca - entendida como a transferência física de bens e serviços - somente pode acontecer quando certas instituições especifiquem e delimitem, antes, os direitos de propriedade sobre os objetos/ serviços trocados. Do mesmo modo, depois que a troca se realiza as instituições continuam a vigir, presidindo as formas de uso dos recursos e protegendo o direito de apropriação dos seus titulares, no presente e no futuro. Nesse sentido, conforme observaram Hartes (1962) e Rutherford (1983) a ação coletiva em Commons estrutura as relações individuais.

Vista de uma perspectiva interna toda transação apresenta as dimensões de oportunidade, que é a alternativa de escolha aberta aos agentes, e de poder, entendido como o grau de persuasão/coerção que o agente pode exercer dentro dos limites colocados pelas alternativas. De outro lado, cada transação é, de um ponto de vista individual e em um mesmo ponto no tempo, um desempenho (performance), uma abstenção (forbearence) e uma renúncia (avoidance).

$\mathrm{Na}$ sua linguagem peculiar, Commons esquematizou os elementos da transação conforme a Figura 1. Nela a ação coletiva faculta a um agente escolher entre dois atos alternativos $\mathrm{AB}$ ou $\mathrm{AC}$. Se o agente escolhe ou é compelido a escolher a alternativa $\mathrm{AB}$, ele renuncia ao ato $\mathrm{AC}$. E se em sua escolha ele se restringe a si mesmo, ou é compelido a isto por ordem, de realizar na sua integridade o desempenho $\mathrm{AB}$, circunscrevendo-o ao ato $\mathrm{AD}$, este é o limite do seu desempenho esta- 
belecido pela abstenção. Segundo Commons, o desempenho é AD; a abstenção é $D B$; a renúncia é AC (Commons, 1995: 78).

Figura 1: Dimensões internas da transação

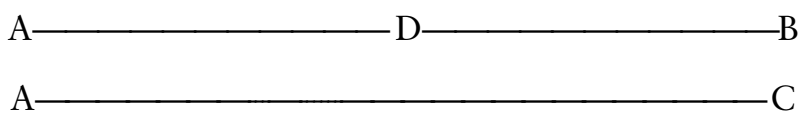

Fonte: COMMONS (1995:78)

A partir dessa concepção, Commons pôde elaborar uma tipologia bastante abrangente das transações predominantes no capitalismo moderno (transação de barganha, transação gerencial, transação distributiva), que se desenvolviam no interior de várias going concern. Este conceito referia-se aos diversos tipos de ação coletiva (a família, a escola, a empresa, o governo, o sindicato, a igreja, etc.) por intermédio dos quais os indivíduos interagiam cotidianamente, tendo por base as regras, regulamentos, costumes, práticas comuns e leis que os regulavam, chamadas de regras de operação da ação coletiva. Estas tinham significados amplos (Rutherford, 1983:727) que se aplicavam tanto a uma específica going concern (uma empresa, por exemplo) quanto a um agregado delas (por exemplo, uma indústria).

As regras de operação da ação coletiva são funcionais e operativas porque discriminam juridicamente o comportamento humano conveniente às transações, e são de quatro tipos (Commons, 1995:85): 1)As que dizem o que os indivíduos devem ou não fazer (regra da compulsão ou dever); 2) As que dizem o que os indivíduos podem fazer sem a interferência de outros indivíduos (regra da permissão ou liberdade); 3)As que dizem o que os indivíduos podem fazer com o auxílio do poder coletivo (regra da capacidade ou direito); 4)As que dizem o que os indivíduos não podem esperar que o poder coletivo faça em seu interesse (regra da incapacidade ou exposição).

Abordadas por esse ângulo, as instituições econômicas (incluindo o mercado) resultavam da regulação das interações e dos conflitos pelas regras de operação da ação coletiva, pois a vida de qualquer individuo acontecia, na sua maior parte, dentro de going concerns. Commons as considerava as unidades conceituais fundamentais, capazes de superar o ponto de partida do individualismo, pois conforme observou (Commons, 1996:335):

"Quando olhamos a questão objetivamente e sem o viés subjetivo dos nossos hábitos e prazeres individuais, percebemos que a verdadeira unidade da teoria econômica não é o indivíduo, mas uma going concern composta de indivíduos em suas várias transações de principal e agente, superior e inferior, empregador e empregado, vendedor e cliente, credor e devedor, fiador e afiançado, patrocinador e beneficiado, etc.”

Era no interior delas que se nascia (um hospital, por exemplo), era dentro delas que o indivíduo desenvolvia suas várias capacidades e habilidades, por exem- 
plo, ao estudar na escola, ao trabalhar na empresa e, no fim da vida, era também em uma going concern que nosso corpo era governado (cemitério). Sendo assim, os indivíduos eram para Commons cidadãos de várias formas de governança. Indivíduos socializados pela ação coletiva (Commons, 1996).

Para ele, as regras de operação da ação coletiva eram o cimento da ordem social que os indivíduos estabelecem no processo de produzir e distribuir direitos de propriedade num contexto de escassez e conflitos. Elas resultaram de um longo processo de experimentação e reiteração de praticas sociais das quais foram selecionadas as mais adequadas, isto é, aquelas com maior aderência aos costumes dominantes. O julgamento de um conflito cria o precedente para que casos similares sejam julgados de igual modo. Institui-se assim a lei comum, que evolui, ela mesma, conforme as modificações nas práticas e costumes sociais. A dinâmica institucional baseada na mudança/consolidação dos costumes foi sintetizada por Ramstad (2001:257), para quem:

"Commons entendia os indivíduos como sendo autointeressados e carregados de propósitos. Mas, ao mesmo tempo, ele considerava que sua mente era, no essencial, socialmente derivada. O ponto de vista de Commons era o de que à medida que os indivíduos repetiam as práticas impostas ou autorizadas pelo controle das regras de operação da ação coletiva, aquelas práticas logo se tornavam habituais, gradualmente enrijecendo em costumes, e eventualmente sendo mesmo percebidas como "naturais". Como consequência, o comportamento será experimentado, conforme a prática costumeira, como sendo amplamente "voluntário", como expressão da "livre escolha". Do mesmo modo, as práticas costumeiras, particularmente aquelas que reforçam os interesses objetivos próprios de alguém, serão tipicamente compreendidas pelo indivíduo como "certas" e "justas". À medida que a natureza subjacente dos conflitos de interesse muda ao longo do tempo devido à inovação tecnológica, à descoberta de recursos, e assim por diante, as regras de operação não serão suficientes para impedir o conflito aberto. Quando o conflito aberto ocorre, as partes em disputa serão geralmente cada uma capazes de identificar práticas costumeiras que, se ampliadas para regular o novo tipo de conflito, resolveriam a disputa em favor de sua própria vantagem percebida. Por isso, as disputas irão geralmente centrar-se sobre a questão de quais práticas costumeiras conflitantes de fato governarão a nova classe de conflitos 'não regulada'."

Sendo assim, indivíduo e estrutura se articulavam na própria definição de instituição, entendida como ação coletiva no controle, liberação e expansão do comportamento individual, instituída pelas práticas costumeiras socialmente selecionadas (Commons, 1996; 1995). É preciso enfatizar com o próprio Commons que o papel das instituições não se reduz à dimensão negativa do controle/coerção (regras da compulsão ou dever), conforme vem insistindo a versão ortodoxa da Economia 
Institucional, mas abarca também a liberação de coerção e restrição, quando, por exemplo, os indivíduos são liberados para empreender e obter lucro (regras da permissão ou liberdade). Ademais, as instituições expandem a ação individual fazendo-as repercutir muito além do espaço e tempo em que tiveram origem.

O que determina o predomínio em um momento de uma dada instituição? A resposta de Commons é inequívoca: um processo de seleção institucional artificial, implicando numa agência que conscientemente interpreta e institui as práticas consideradas razoáveis. Conforme observou Gonce (1971:87), referindo-se a Commons:

"Em sua opinião, os fenômenos sociais são em grande medida o resultado da ação coletiva deliberada, não do autointeresse; da seleção artificial, e não da natural; das convenções humanas em evolução, e não da natureza."

\section{DIREITO E ECONOMIA}

Embora seja no livro Fundamentos Legais do Capitalismo, publicado em 1924, onde mais exaustivamente Commons discutiu e analisou as relações entre lei e economia, esta temática, pode-se dizer, encontra-se presente em praticamente todas as suas obras e distribuída ao longo de sua vasta produção científica. Parte desse interesse tinha a ver, como foi dito, com seu ponto de vista crítico da ortodoxia econômica, e parte com o aspecto político do seu pensamento, influenciado pelo reformismo social defendido pelo movimento gospel do final do século XIX, do qual foi um dedicado militante, e também por sua ampla experiência prática como assistente das comissões legislativas do estado de Wisconsin, onde, por muito tempo, pôde analisar os processos e o modus operandi do judiciário em questões que envolviam, em especial, a atribuição de valor a bens e direitos (Hartes, 1962). Esses motivos se misturam em graus variados para explicar seu interesse pelo Direito, meio pelo qual acreditava se materializariam as reformas sociais que advogava para seu projeto de capitalismo "razoável” (Bazzoli, 1999), (Chasse, 1986).

Commons esforçou-se largamente para fazer ver aos economistas como o direito e a economia lidavam com muitos elementos comuns e apenas um divergente, conforme ilustra o Quadro 1.

Quadro 1: Elementos de convergência e de divergência entre as disciplinas de Economia e Direito.

\begin{tabular}{|l|c|c|}
\hline & ECONOMIA & DIREITO \\
\hline Escassez & $X$ & $X$ \\
\hline Futuridade & $X$ & $X$ \\
\hline Costume & $X$ & $X$ \\
\hline Soberania & $X$ & \\
\hline Eficiência & $X$ & \\
\hline
\end{tabular}

Fonte: elaboração própria do autor a partir de COMMONS, 1996. 
Ele acreditou, contudo, que o elemento de divergência foi tão poderoso que obscureceu os demais. Commons atribuiu o divórcio entre as ciências Econômicas e o Direito a duas causas fundamentais: em primeiro lugar, às realizações materiais do capitalismo no século XIX, que realçaram os aspectos técnicos e quantitativos da produção material, induzindo, dessa feita, o pensamento econômico a priorizar as questões relativas à eficiência. Nessa dimensão a Economia reduziu-se a uma engenharia de processos materiais, de sistemas mecânicos regulados por leis naturais (o exemplo mais flagrante disso talvez seja a antiga concepção de firma como uma função de produção). Em segundo lugar, ao predomínio do individualismo, que na versão de Bentham ofereceu um argumento ético ao egoísmo privado, por afirmar que a maior produção de riqueza por indivíduos autointeressados era equivalente ao principio ético da máxima felicidade de todos.

$\mathrm{Na}$ visão de Commons, essa separação empobreceu sobremaneira a Ciência Econômica, pois as demais dimensões que produziam a convergência foram eclipsadas. Desse modo, a escassez foi tratada pela tradição econômica a partir dos termos oferta, demanda e preços relativos, cujas mudanças em qualquer uma das três variáveis de escassez exigiam sua adequação por parte das outras duas num jogo mecânico e autoimposto. Ela desconsiderou a abordagem dos juristas que encontraram na escassez a fonte da propriedade, pois o direito nenhuma importância tem numa situação de abundância. Ele somente se torna relevante quando a escassez introduz os problemas de delimitação de direitos de propriedade para excluir alguns do uso e disposição dos recursos. O resultado disso foi a redução da natureza transacional das relações que os homens estabelecem entre si à troca, conforme já se referiu. Nesse sentido se entende porque Commons lamentou profundamente os ataques de Bentham a Blackstone - um dos primeiros estudiosos da lei comum na Inglaterra - e o desprezo a que foi relegada a teoria dos direitos de propriedade de MacLeod (Commons, 2003).

Do mesmo modo, o costume como base das práticas comuns e da lei comum foi substituído pela "razão", como aspecto explicativo e ponto de partida do comportamento humano. A perda aí foi enorme, pois se desconsidera que a economia emerge de práticas costumeiras de vários grupos e classes em suas transações diárias para criar e se apropriar de renda, das mais variadas formas.

A futuridade, que diz respeito ao modo como o futuro (que ainda não existe) determina as ações e comportamento no presente, foi substituída por uma concepção de tempo percebida como um fluxo de eventos que procede inevitavelmente do antecedente para o consequente, conforme a analogia das ciências físicas. O resultado disso é que foram eliminados do comportamento humano as dimensões da incerteza e o papel das instituições em prover algum alicerce para as expectativas em relação às transações.

A soberania - que trata da "vontade coletiva" da sociedade e que evoluiu historicamente por diferentes formas até chegar ao Estado moderno (Commons, 1995) - foi abordada pela ortodoxia econômica nos termos estabelecidos pelo liberalismo clássico, que a considerava negativamente, como o ônus a ser pago em termos de privação da liberdade natural para a manutenção da vida ou da proprie- 
dade privadas. Todavia, em Commons, esse agente é importante porque o comportamento humano embute as dimensões expectacionais e temporais. Por se desdobrar no tempo, o comportamento que ocorre no presente somente existe como expectativa, como vir a ser. No intervalo de tempo entre uma intenção de comportamento no presente e sua materialização no futuro, os agentes podem deixar de cumprir deliberadamente ou não a promessa de um dado comportamento. Nesse caso, o interesse parcial dos envolvidos poderia introduzir "a guerra de todos contra todos" e inviabilizar a transação. Para Commons, as regras compulsórias do Estado ofereciam a "segurança expectacional" (Ramstad, 2001:257) aos agentes, sem a qual eles não desejariam voluntariamente transacionar uns com os outros.

O Estado era concebido por ele como uma going concern especial, que possuía o monopólio da violência legítima, cujo exercício cabia a uma hierarquia de funcionários autorizados. Commons compreendia o papel da lei como um ancoradouro que antecipava e em certa medida assegurava aos agentes o que a coletividade entendia como comportamento esperado e adequado no futuro. Nesse sentido, nas palavras do autor, as leis são "expectativas previsíveis" (Commons, 1995:90). Commons tinha muito clara a distinção entre lei e direito, a primeira sendo caracterizada por ele como apenas vontade no vácuo, uma promessa de ação coletiva caso o comportamento esperado não se materialize, ao passo que a segunda é a vontade em ação dos funcionários do Estado. Se a lei é a vontade no vácuo, o direito é esta mais a vontade em ação dos servidores públicos. Para Commons a dimensão real dos direitos e deveres dependia fundamentalmente do Estado.

Como se vê essas regras de operação da ação coletiva que presidem a estrutura e ação do Estado subvertem a interpretação tradicional, que vem de Hobbes, segundo a qual a criação da soberania do Estado significou a privação de pelo menos uma parcela da liberdade humana. Para Commons, ao contrário, o Estado é a garantia e ampliação da liberdade, assegurada pelo exercício das regras de operação aceitas pela sociedade. Combatendo a tradição jurídico-filosófica que no século XVIII criou o ideal de direitos humanos naturais, ou seja, anterior ao Estado, Commons insiste em que os direitos que os homens estabelecem nas suas transações diárias são aqueles que somente podem existir quando o Estado é chamado pelos cidadãos a garanti-los. Só existe direito pela ação do Estado. Ou conforme expressou Commons (1995:385):

"A teoria econômica, assim como a teoria jurídica, começa com a liberdade ao invés de iniciar pelo propósito. A liberdade é a ausência individual de coerção física. Mas o propósito público é aquele de dar aos indivíduos, por meio das regras comuns que ligam todos sob circunstâncias similares, o poder de solicitar do governo a aplicação da sua vontade. Este propósito tem funcionado tão regularmente, especialmente na Inglaterra após a Act of Settlement, que os direitos que são assim produzidos dão a impressão de serem direitos naturais do homem, no sentido, não de um ideal que o homem deve possuir com o auxílio do governo, mas de algo que ele previamente possuía por natureza e do qual foi privado 
pelo governo. Esta noção anarquista da vontade humana era inseparável da noção anarquista de propriedade que a acompanhava. Pois a propriedade era também um direito natural, já que o homem não poderia viver sem a possessão e posse exclusiva de coisas físicas que consome ou com as quais trabalha. E o governo privou os indivíduos tanto da liberdade quanto da propriedade de dois modos: por meio das legislações restritivas ou protetoras e por meio de doações de franquias para as corporações. Estes conceitos de liberdade e soberania culminaram na Revolução Francesa, que estabeleceu a propriedade privada e proibiu toda associação.”

Em síntese, para Commons a ação coletiva (na forma moderna do Estado) diz respeito a sujeitos carregados de propósitos variados que necessitam relacionar-se (daí as transações), sob regras básicas comuns, para fazer valer seus propósitos. Ademais, o Estado ou formas pretéritas de soberania emergem simultaneamente à dinâmica institucional, que é a passagem de uma para outra regra de operação. Para ele, o Estado era elemento constitutivo da sociedade e um dos seus produtos, emergindo de dentro dela. Nele não há dicotomia entre Estado e Sociedade, liberdade e autoridade, etc. Todas as páginas dedicadas por Commons ao estudo da soberania moderna (Estado moderno) — de que é exemplo notável a sua análise de como grupos sociais por meio da ação coletiva forçaram a Coroa britânica a abandonar seu monopólio sobre o processo de ajustamento institucional, contido em Fundamentos Legais do Capitalismo - são uma tentativa exaustiva para mostrar que é incorreto tratar as leis como parâmetros ou como constante num sistema de relações. Ao tratar a lei como variável, Commons endogenizou o Estado e cobrou das Ciências Econômicas o tratamento analítico e conceitual mais adequado para isso.

Isto somente poderia ser alcançado por um movimento de subversão do pensamento estabelecido a ponto de definir como tarefa fundamental a construção das bases para a compreensão da emergência da ordem econômica legal, a partir de indivíduos "institucionalizados". Daí a ênfase, no pensamento econômico de Commons, no estudo da lei costumeira e positiva. Era sua crença de que o ponto de partida essencial era o de restituir as pontes entre o Direito e a Economia, que tornavam compreensível o capitalismo moderno.

\section{A SELEÇÃO ARTIFICIAL NA INSTITUCIONALIZAÇÃO DE NOVAS FORMAS DE RIQUEZA}

Essa concepção do papel do Direito na análise econômica, aliada à sua ampla experiência com questões jurídicas, lhe proporcionou compreender os mecanismos pelos quais as práticas sociais costumeiras são selecionadas artificialmente, bem como o papel essencial nesse processo do poder judiciário e da lei.

Para ele noções jurídicas como propriedade, liberdade e valor modificavam-se 
em consonância com aquelas mudanças que aconteciam na sociedade, mas não de maneira mecânica e reflexa. Ao mesmo tempo em que se adequavam, as leis e sua interpretação ampliavam as possibilidades das relações humanas, provocando, desse modo, alterações também nelas. Em outras palavras, as leis ampliam o escopo e significado das transações.

Commons percebeu que os juízes tendem a julgar a partir de uma interpretação da legislação que promova a conduta "razoável", entendida como aquela mais amplamente enraizada na prática costumeira comum, e cuja generalização contenha os elementos de superação dos conflitos e do estabelecimento da ordem, sempre considerados provisoriamente. Desse modo, os juízes ao julgar olham para as práticas costumeiras capazes de prover certos compromissos de estabilidade e eficiência a partir de elementos éticos/ideológicos acerca do que é "bom", "justo"e "razoável".

Alguns exemplos, retirados dos Fundamentos Legais do Capitalismo, podem auxiliar no esclarecimento desse tipo de relação. Commons cita o caso da mudança de interpretação sobre os conceitos de liberdade e propriedade feita pela Suprema Corte dos EUA a partir do Caso dos Matadouros (1872). Em Nova Orleans, a prefeitura havia, por razões de saúde pública, autorizado a uma empresa privada o monopólio do abate de carne da cidade. Esta passou a cobrar dos açougueiros uma taxa pelo uso das suas instalações de abate. Contra essa decisão, os açougueiros da cidade recorreram à Suprema Corte, reivindicando a proteção garantida pelas décima terceira (que proibia a escravidão e a servidão involuntária, exceto nos casos de punição por crime) e décima quarta (que proibia um estado de privar qualquer pessoa da vida, liberdade ou propriedade sem o devido processo legal) emendas da Constituição. Em outras palavras, os açougueiros argumentaram que a decisão do poder executivo restringia-lhes a liberdade de escolher onde abater o gado e, por conseqeência, reduzia o rendimento que auferiam da sua propriedade.

A decisão da Suprema Corte exigiu a interpretação dos sentidos dos conceitos de liberdade e propriedade contidos na Constituição. Segundo Commons, embora dividida, a maioria dos juízes decidiu contrariamente à reivindicação dos açougueiros, argumentando que naquele caso não houve privação de liberdade e propriedade porque o significado de liberdade contido nas duas Emendas era o de liberdade da escravidão ou da servidão pessoal, e o de propriedade significava a coisa física conservada exclusivamente para o uso próprio de alguém. Como os açougueiros não foram escravizados (ou submetidos a algum tipo de servidão involuntária) nem privados dos seus bens, seu pleito foi negado. Para Commons (1995:15), a decisão da Corte baseou-se em noções restritas de liberdade (ausência de servidão involuntária) e propriedade (posse e titulação de valores de uso para utilização do seu proprietário).

Cerca de dezoito anos depois (em 1890), no entanto, uma nova demanda jurídica obrigou a Suprema Corte a rever sua decisão anterior. Tratou-se do Minnesota Rate Case, no qual representantes de uma empresa ferroviária contestaram o poder do Estado de Minnesota de fixar as tarifas dos serviços ferroviários. Reivindicando a proteção da décima quarta e décima quinta Emendas, os reclamantes argumentaram que a fixação das tarifas pelo governo estadual restringia a liberda- 
de e ameaçava a propriedade, cujo valor dependia dos preços pelos quais eram vendidos seus serviços. Dessa vez a Suprema Corte julgou o pleito favorável aos proprietários de ferrovias argumentando que

Não apenas as coisas físicas eram objeto de propriedade, mas o rendimento potencial esperado daquelas coisas é propriedade; e a propriedade é tirada do seu proprietário não apenas pelo poder do domínio eminente, que subtrai títulos e posses, mas também sob o poder de polícia que lhe subtrai o valor de troca. Privar os proprietários do valor de troca de sua propriedade é equivalente a privá-los da sua propriedade. (Commons, 1995:16).

Commons analisou essa mudança como o embrião das transformações nas noções de liberdade, propriedade e valor da sociedade, mais condizentes com o estado dos negócios dominado pela grande empresa e com as novas formas de riqueza que com ela emergiam. Em seu juízo, ao considerar propriedade qualquer rendimento potencial esperado das coisas, a Suprema Corte ofereceu parâmetros bastante amplos para fundar as bases legais sobre as quais pôde se apoiar a expansão capitalista nos EUA. Ao mesmo tempo, a decisão sinalizou para a permeabilidade da lei, que incorporou noções e costumes do mundo dos negócios aos conceitos de liberdade, propriedade e valor. ${ }^{2}$ Ademais, esses três conceitos passaram a ser indissociáveis, uma vez que a propriedade no sentido acima definido implicava a liberdade para acessar mercados e fixar preços (valores de troca). Propriedade, liberdade e valores de troca (ativos) tornaram-se apenas aspectos da transação. É fácil perceber como, na percepção de Commons, estão imbricados economia e lei.

O aspecto mais inovador desse conjunto de interpretações da Suprema Corte foi o de que a nova concepção de propriedade (como valor de troca) acrescentou duas dimensões àquela física: a incorpórea e a intangível. Esta caracterizando os valores de troca esperados de algo, seja propriedade tangível ou não, e aquela representando as promessas de pagamento. Ambas carregam a característica de futuridade: ações imersas em instituições no presente mas cujos desdobramentos em termos de posse física se darão no futuro. Commons percebeu que a "desmaterialização" da riqueza e sua diversificação por novas formas somente se podia fazer sob o amparo do reconhecimento social dessas formas através das instituições.

Essas duas novas dimensões da propriedade exigiram, também, uma modificação na compreensão social do conceito de liberdade. Do conceito restrito de proibição da servidão involuntária, ela ampliou-se, significando ausência de restrição, compulsão ou dever. Afinal, a propriedade de nada valia se o seu proprietário (ou seus supostos clientes) fosse impedido de acessar os mercados onde pudesse comprar e vender. Se a propriedade significa algo que pode ser comprado e vendi-

\footnotetext{
${ }^{2}$ De acordo com Commons (1995:14), "desse modo, os novos significados de propriedade e liberdade foram encontrados em Adam Smith e nos costumes dos negócios, e não na Constituição dos EUA”.
} 
do, e a liberdade de alguém pode ser comprada e vendida, esta é um ativo e, desse modo, a liberdade é propriedade (Commons, 1995).

$\mathrm{Na}$ verdade, argumentou Commons, as pessoas transferem parte de sua liberdade quando realizam transações. No caso de um empréstimo, em que o tomador compromete-se a pagar $1.000 \mathrm{em}$ um ano, o que foi vendido e comprado não foi uma coisa física, mas a promessa de um certo comportamento futuro: a de pagar o valor do empréstimo e seus custos (juros). Negociam-se obrigações positivas. Isto nada mais é do que negociar graus de liberdade. De um lado, o tomador abre mão de comportar-se de um modo não adequado à transação (por exemplo, não pagá-la), ao passo que o emprestador ganha a liberdade de acionar a justiça caso o comportamento esperado não se materialize.

Numa transação que envolve a venda de uma empresa (comercial ou industrial), além da sua dimensão física, vende-se a clientela e a marca fantasia, uns e outros intangíveis. Novamente ai o que se vende é parte da liberdade do antigo proprietário, que se exime de competir com o novo e de usar sua marca. Esse caso é ainda mais particular porque o que se compra na verdade é a oportunidade de lidar com os clientes e de ganhar com o uso da marca. Compra-se do proprietário sua promessa de nada fazer em relação aos clientes e à marca adquirida, sua abstenção de agir em relação a eles. De outro lado, compra-se a oportunidade de lidar com os clientes e de vender-lhes produtos exclusivamente, isto é, sem a interferência do vendedor.

Ademais, para Commons, a propriedade invisível (intangível e incorpórea) não era exceção, mas o traço mais característico e importante do capitalismo. O mais característico porque a propriedade invisível

"Aparece de várias maneiras. As obrigações vão de simples promessas inferidas de atos simples a elaborados títulos que atam em compromisso um negócio ou uma nação por um século. As oportunidades vão de escolhas simples entre alternativas feitas diariamente em cada transação à oportunidade de expansão duradoura de mercados, ao direito de patente, ao direito a continuar no negócio, ao direito ao mercado de trabalho, ao direito à liberdade de contrato, e a muitos tipos de autorizações públicas, licenças para as empresas e concessões para utilidades públicas. (Commons, 1995: 24).”

Era também o traço mais importante do capitalismo por que

"O capital invisível de muitos negócios é mais valioso do que todas as máquinas, construções e estoques e, de fato, se o capital invisível perde o seu valor, todo o capital visível cairá em seguida ao valor de ferro velho e sucata. Não seria incorreto dizer que todo capital é valor invisível, na medida em que ele é o valor presente, não das coisas físicas, mas das esperanças no futuro, erigidas por meio da confiança nas agora invisíveis, mas esperadas transações no futuro. (Commons,1995: 25)." 
Inextricavelmente vinculado à propriedade, liberdade e valor estavam a noção de poder. Ela apareceu inicialmente de forma implícita, na medida em que as transações envolviam relações de persuasão e coerção. O poder estava presente, portanto, em toda transação. Para Commons o exercício do poder econômico privado acontece simultaneamente ao da liberdade. É, na verdade, uma das suas expressões. Ao escolher livremente entre alternativas está-se, ao mesmo tempo, exercendo poder. Ou melhor, exercitando graus de poder, conforme foi antecipado na Figura 1. $\mathrm{O}$ trabalhador que recebe $\mathrm{X}$ por hora de trabalho e encontra quem está disposto a pagar-lhe $\mathrm{X}+1$ pela mesma hora, caso opte pelo segundo empregador está exercendo, além da sua liberdade, poder. ${ }^{3} \mathrm{O}$ mesmo vale para a empresa ferroviária que, podendo optar por pelo menos duas possibilidades, cobra o valor mais alto pelo seu bem ou serviço.

Commons o chamou de poder de troca, que é medido pela proporção/taxa de moedas em que as trocas são estabelecidas. Há, ainda, uma expressão do poder associado à liberdade de escolha, à oportunidade. Através dela pode-se obter um excedente na troca que não tem fundamento nos custos em si. Nos exemplos acima, caso o empregador e os clientes da estrada de ferro não tenham alternativa aos serviços e preços cobrados pelos ofertantes (o empregado e a empresa ferroviária), estes poderão obter um excedente econômico sem custo, derivado do poder da liberdade e propriedade.

Apesar disso, o poder foi inicialmente pensado pela justiça como estando separado da propriedade e liberdade. O poder era entendido com o poder do soberano (Estado), usado para compelir a obediência. Ou a concessão desse poder, sob condições e regulação, a terceiros privados. O poder econômico privado originário da propriedade e da liberdade e exercido por um cidadão contra o outro somente foi reconhecido pelo judiciário norte-americano em 1876, no caso Munn contra Illinois. Nesse litígio, a legislatura do estado de Illinois autorizou o executivo estadual a regular os preços dos serviços cobrados por uma empresa privada encarregada de armazenar e distribuir grãos. Armazéns se tornaram estratégicos no controle dos preços dos grãos embarcados no noroeste do país em função da sua localização e das características do próprio negócio. O importante na decisão da Suprema Corte foi que uma empresa privada que não tinha ou dependia de concessão pública para funcionar teve sua liberdade de fixar preço reduzida pelo poder de polícia do estado. Conforme Commons (1995:34):

"A decisão no caso Munn versus Illinois reconheceu pela primeira vez o poder econômico da propriedade, ou o poder para reter, originado das condições econômicas, como distinto do poder físico da soberania, ou o poder para compelir, exercido no interesse de cidadãos como seu

\footnotetext{
${ }^{3}$ Estava claro para Commons que o exercício de graus de poder é muito diferente entre os indivíduos, principalmente os indivíduos naturais (pessoas físicas) e os indivíduos artificiais (pessoa jurídica), com clara vantagem para os últimos. Ver COMMONS, 1995, p.72.
} 
privilégio ou 'liberdade...'.A concessão de poder aos cidadãos para fixar preços vinha agora não da soberania diretamente, mas indiretamente da própria propriedade do cidadão, à qual aquele poder econômico se vincula. Fez-se a transição de um monopólio legal, a antiga 'liberdade' do cidadão para exercer o poder soberano, para um monopólio 'natural', a liberdade moderna para exercer o poder econômico, uma vez que ela deriva automaticamente das condições econômicas, ao invés de um ato intencional da soberania."

Os exemplos comentados revelam o papel crucial das instituições (o judiciário e seu modo de operação, no caso) na criação e legitimação de formas de riqueza inovadoras, realizando a seleção artificial das práticas sociais conflitantes e acreditadas como mais adequadas às relações ordeiras de uma transação. Eles também capturam a natureza de dupla mão na determinação da lei e da ação do Estado. De um lado, sua origem nos costumes e, de outro, na ampliação desses pelo Estado.

Hodgson (2003) ao situar a contribuição de Commons criticou-lhe o viés de priorizar exclusivamente as instituições formais, aquelas cuja existência e funcionamento dependiam do amparo legal e do Estado, negligenciando o papel e importância das instituições informais e extralegais. Com matizes diferentes, esse tipo de argumento foi levantado contra Commons também por Rutherford (1983). Tais observações devem ser, contudo, relativizadas. Como é reconhecido pelos próprios críticos, Commons não poderia deixar de reconhecer a existência e importância das instituições informais, pois elas existem antes, como hábito e costume, da sua conversão em instituições formais, e continuam sendo importantes como elemento impulsionador das mudanças institucionais, cuja base era o "estabelecimento costumeiro de disputas" (Chasse, 1986:773).

É certo, contudo, que Commons somente se interessou por elas na etapa genética, voltando-se, prioritariamente, para as instituições formais. Em parte isso pode ser explicado pela necessidade de Commons extremar sua interpretação do capitalismo daquela derivada da tradição clássico-liberal, que realçava, como se viu, a possibilidade de auto-organização a partir de indivíduos livres e racionais. Adicionalmente, deve-se referir à crença de Commons de que as instituições informais não aplicam sanções suficientemente fortes a ponto de serem determinantes do comportamento humano (Gonce, 1971:84). Mas uma razão mais decisiva, defendida neste artigo, prende-se à tentativa de Commons de restabelecer a convergência entre Economia e Direito perdida quando — sob a influência do individualismo e das metáforas das ciências físicas - a Economia voltou-se exclusivamente ao estudo da dimensão de eficiência das relações humanas no processo de produção e distribuição da riqueza material.

\section{CONCLUSÕES}

A visão de Commons da ordem econômica no capitalismo se afasta daquela 
que a deriva da ação espontânea de agentes livres e racionais. Seu ponto de vista foi o de tratar a ordem econômica como embebida no quadro maior das relações sociais, o que exige determinadas formas de regulação social. Nesse sentido, sempre que a atividade econômica e as transações se desenvolvem, arranjos institucionais novos, que emergem dos costumes, são instituídos para prover de ordem e legitimidade as novas praticas e interações sociais.

Nesse contexto, as reflexões de Commons a respeito do modo como emergem as novas práticas de criação e distribuição de riqueza, bem como as formas que elas assumem são de extrema importância e atualidade, pois ao apontar para a desmaterialização do valor, na medida em que este depende do comportamento futuro esperado dos atores sociais, ele antecipou as dificuldades que o tempo introduz, ao produzir incerteza, nas relações econômicas. Ao mesmo tempo, pôs em relevo o papel da lei como ancoragem, sempre provisória, para as expectativas em relação ao comportamento e compromissos futuros assumidos pelos indivíduos em suas transações.

Cabe observar, ainda, que o capitalismo sobre o qual Commons reflete é aquele no qual a riqueza se expressa fundamentalmente em ações, títulos, ativos financeiros, sistemas de crédito e débito e nas marcas e patentes. São esses capitais invisíveis que tomam o lugar central na criação e distribuição da riqueza, pois eles mobilizam essencialmente direitos sobre a entrega/recebimento do controle legal sobre mercadorias. Nesse aspecto, Commons nos mostrou que valores como liberdade, propriedade, valor de troca e poder não são exclusivos do capitalismo, mas este modificou e ampliou seu significado, tornando-os adequados ao processo de valorização das coisas, ainda que invisíveis. As leis e o Direito ampliaram as oportunidades para o desempenho individual. Paradoxalmente, ao mesmo tempo em que foram ampliadas, as noções de liberdade, propriedade e poder exigiram sua restrição, na forma de ação coletiva, pelo Estado. Isto porque as transações necessitam de regras que estabeleçam a conduta/comportamento esperados numa transação e imponham sanções caso não sejam observados.

Aspecto importante realçado por Commons é o de tratar o Estado como um ator endógeno do processo transacional, cuja presença e intervenção viabilizam e que é mesmo pré-condição para que as transações aconteçam. Sua visão do que ele chamava de "soberania" não colocava a ênfase exclusivamente sobre os aspectos coercitivos e repressores do Estado, embora deles tivesse consciência e plena percepção da sua importância. Ao contrário, Commons a percebia como produto dos hábitos, práticas e costumes diários dos indivíduos. Desse modo, a soberania colocava-se tanto como um elemento coercitivo como de liberdade, de deveres, mas também de direitos e, mais importante, enraizado na ação coletiva.

Essa perspectiva o distancia radicalmente da economia ortodoxa de ontem e de hoje. Nem a versão novo-institucional dessa — na forma, por exemplo, da economia dos direitos de propriedade ou da moderna Economia do Direito - foi capaz de promover uma reconciliação. Lamentavelmente, a aplicação da microeconomia neoclássica ao estudo da lei, ainda que para muito além dos tradicionais estudos da legislação antitrust e suas conexões, trouxe pela porta dos fundos aqui- 
lo que Commons tentou pôr para fora pela porta da frente: a estruturação das questões legais em termos individuais (racionalidade substantiva) e de eficiência.

\section{REFERÊNCIAS BIBLIOGRAFICAS}

BAZZOLI, L (1999) — L'economie politique de John R. Commons: essai sur l'institutionnalisme en sciences sociales. Paris: Editions L'Harmattan.

BASLÉ, M (1993) — “Mise en perspective de L'institutionnalisme de quelques économistes allemands et américains". Economie Apliquée, 46(4): 159-176.

CHASSE, J.D (1986) - “John R. Commons and the democratic state”. Journal of Economic Issues, 20 (3): $759-784$.

COMMONS,J.R (1924 [1995] — Legal foundations of capitalism. New Brunswick:Transaction Publishers.

COMMONS,J.R (1934[ 2003] — Institutional Economics: its place in political economy. New Brunswick:Transaction Publishers.

COMMONS, J.R (1931 [1996] — "Institutional Economics”. IN: Rutherford, M; Samuels, W. J. (orgs.) John R. Commons: Selected Essays (vol II). London: Routledge:-443-452.

COMMONS, J.R (1925[1996] — "Law and Economics". In Rutherford, M; Samuels, W. J. (orgs.) John R. Commons: Selected Essays (vol II). London: Routledge: 331-342.

COMMONS, J.R (1932[1996] — “The problem of correlating law, economics and ethics”. IN: Rutherford,M; Samuels, W. J. (orgs.) John R. Commons: Selected Essays (vol II). London: Routledge: 453-473. DUGGER, W (1990) — "The new institutionalism: new but not institutionalist”. Journal of Economic Issues, 24(2): 423-431.

FOREST, J; MEHIER,C (2001) — "John R. Commons and Herbert A. Simon on the concept of rationality”. Journal of Economic Issues, 35(3): 591-605.

GONCE, R.A (1971) — “John R. Commons's legal economic theory”. Journal of Economic Issues, 5(3): 80-95.

HARTES JR, L.G (1962) — John R. Commons: his assault on laissez-faire. Oregon: Oregon State University Press.

HODGSON, G.M (2000) — "What is the essence of institutional economics?". Journal of Economic Issues, 34(2): 317-330.

HODGSON, G.M (2003) - "John R. Commons and the foundations of institutional economics". Journal of Economic Issues, 37(3): 547-575.

HODGSON, G.M (1998) -“The approach of institutional economics”. Journal o f Economic Literature, 36(2): 166-192.

KLEIN, P.A (1990) — "Institutionalism as a school- a reconsideration". Journal of Economic Issues, 24(2): 381-388.

MITCHELL, W.C (1935 [1950] — “Commons on institutional economics”. IN: Mitchell, W.C. The backward art of spending money. New York: Augustus M. Lelly, Inc: 313-341.

MYRDAL, G (1978) — “Institutional Economics". Journal of Economic Issues, 12 (4):771-783.

PESSALI, H \& FERNANDEZ, R (1999) — "Institutional Economics at the micro level? What transaction cost theory could learn from original institutionalism (in the spirit of building bridges)". Journal of Economic Issues, 33(2): 265-275.

RAMSTAD, Y (2001) - “John R. Commons's reasonable value and the problem of just price”. Journal of Economic Issues, 35(2):253-277.

RENAULT, M (1997) — “Pragmatisme et institutionnalisme: des fundaments épistémologiques et méthodologiques pour l'évolutionnisme en économie”. Economie Appliquée, 50(3): 23-52.

RUTHERFORD, M (1983) — “J.R.Commons's institutional economics”. Journal of Economic Issues, 17(3): 721-744. 